Military Technical College Kobry El-Kobba

Cairo, Egypt

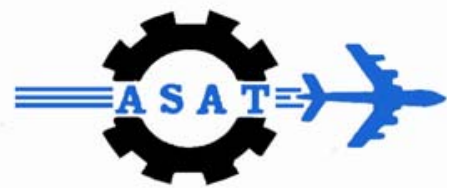

12-th International Conference

on

Aerospace Sciences \&

Aviation Technology

\title{
EFFICIENT FUZZY LOGIC DESIGN TO IMPROVE DYNAMIC STABILITY OF LATERAL LANDING AUTOPILOT
}

\author{
Ali M. Yousef *
}

\begin{abstract}
In this paper, lateral beam guidance autopilot system has considered as an aerospace application. The construction and derivation of the equations of motion is considered and partial modification in internal construction of the autopilot has performed. Proposed efficient fuzzy logic and robust compensator control have applied to the lateral beam autopilot system to increase damping oscillation. Moreover, for comparisons the conventional optimal control has designed and evaluated. The robustness and convergence of the system due to the stability derivatives variations are studied. Efficient fuzzy logic control is preferred for this system where, it does not require the complex mathematics associated with conventional control techniques. The digital simulation results show the effectiveness of the proposed fuzzy logic and LQG controllers in terms of fast damping the oscillations, small settling time, and less over/under shoots.
\end{abstract}

Key Word: Aircraft lateral autopilot system, Fuzzy logic control, optimal control. LQG control

\footnotetext{
* Assistant prof. in Electric Eng., Dept., Faculty of Engineering Assiut University, Assiut- Egypt E-mail: Drali_yousef@yahoo.com
} 


\section{Nomenclature}

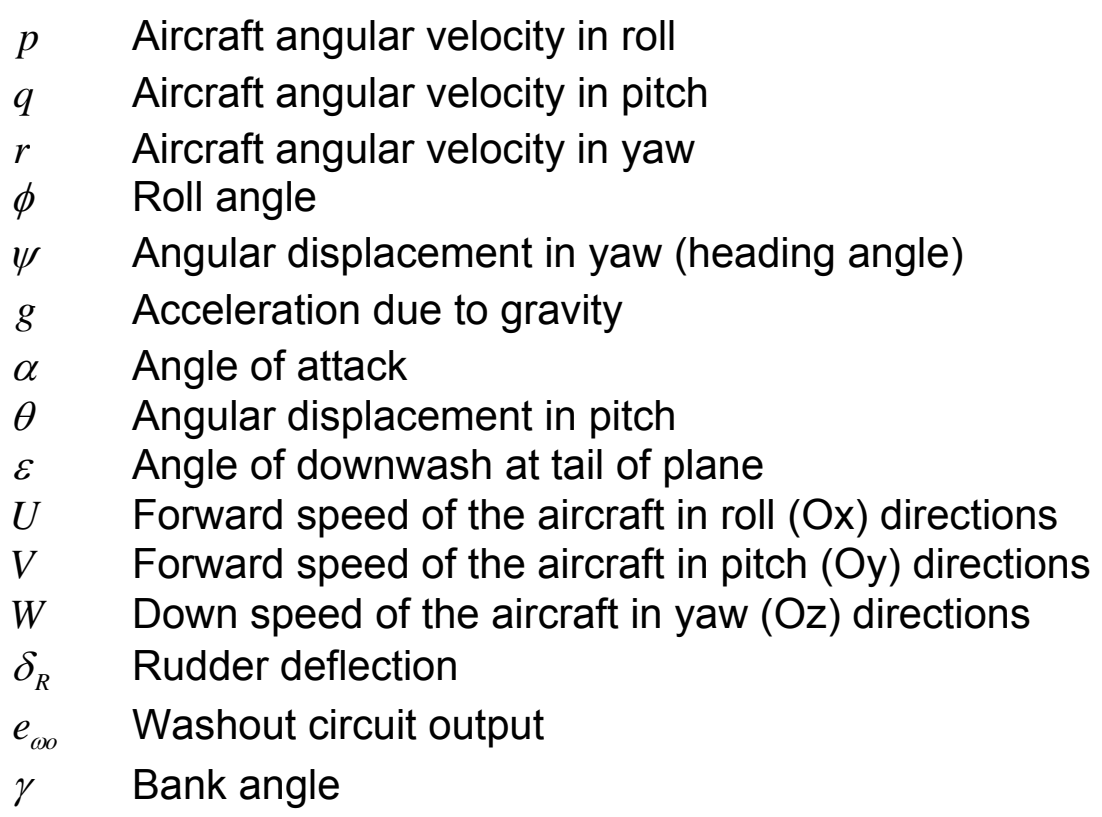

\section{INTRODUCTION}

Lateral beam guidance autopilot system was study with the static fuzzy logic controller with both types direct and indirect methods [1]. There are three basic asymmetric motions of an aircraft: firstly sideslip, roll, and yaw [2]. The corresponding velocities are the sideslip velocity $v$ of the center of gravity $O$, the rate of roll $p$ about the axis $O x$, and the rate of yaw $r$ about the axis $O z$. The aerodynamic forces and moments due to these velocities can be expressed in terms of non-dimensional derivatives. Consider an airplane in flight, as sketched in Fig. 1a. The center of gravity (the point through which the weight of the complete airplane effectively acts) is denoted as CG. The xyz orthogonal axis system is fixed relative to the airplane: the $x$-axis is along the fuselage, the $y$-axis is along the wingspan perpendicular to the $\mathrm{x}$-axis, and the $z$-axis is directed downward, perpendicular to the $x-y$ plane. The origin is at the CG. The translational motion of the airplane is given by the velocity components $\mathrm{U}, \mathrm{V}$ and $\mathrm{W}$ along the $\mathrm{x}, \mathrm{y}$, and $\mathrm{z}$ directions, respectively $[3,4]$.

Note that the resultant free stream velocity $V_{\infty}$ is the vector sum of $U, V$, and $\mathrm{W}$. The rotation motion is given by the angular velocity components $p, q$, and $r$ about the $x, y$, and $\mathrm{z}$ axes, respectively. These rotational velocities are due to the moments $L^{\prime}, M$, and $N$ about the $\mathrm{x}, \mathrm{y}$, and $\mathrm{z}$ axes respectively. Rotational motion about the $\mathrm{x}-$ axis is called roll; $L$ and $P$ are the rolling moment and velocity respectively. Rotational motion about the $y$-axis is called pitch; $M$ and $q$ are the pitching moment and velocity respectively. Moreover, the rotational motion about the z-axis is called yaw; $\mathrm{N}$ and $\mathrm{r}$ are the yawing moment and velocity[5].

There are three basic controllers on an airplane- the ailerons, elevator, and rudder, which are designed to change and control the moments about the $\mathrm{x}, \mathrm{y}$, and $\mathrm{z}$ axes. 
These control surfaces are shown in Fig. 1-b,c, they are flap like surfaces that can be deflected back and forth at the command of the pilot. The ailerons are mounted at the trailing edge of the wing, near the wingtips. The elevator is located on the horizontal stabilizer. In some modern aircraft, the complete horizontal stabilizer is rotated instead of just the elevator (so-called "flying tails"). The rudder is located on vertical stabilizer, at the trailing edge. Just as in the case of wing flaps. The rudder is deflected to the right, creating a leftward aerodynamic force on the tail, thus contributing to the yawing moment $\mathrm{N}$.

In this paper, the rudder motion and control is concentrated. Proposed efficient fuzzy logic and LQG controllers design and application to the lateral beam system and rudder motion to increased the damping oscillation in sideslip angle, angular velocity in yaw and roll direction[6-9]. For comparison, the conventional optimal feedback control has designed and applied to the system. The fuzzy control is simple and effective damping for aerospace application. Using MATLAB fuzzy logic toolbox for simulation process $[10,11]$.

\section{LATERAL BEAM GUIDANCE MODEL}

Two models has evaluated in this study as the following:

\subsection{Model-1: Classical Automatic Lateral Beam Model}

In derivation of the lateral equation of motion of aircraft, suppose $\psi$ and $\phi$ instead of $r$ and $p$ respectively but this assumption is valid only for small perturbation from equilibrium [1]. These equations has described as:

$$
\begin{aligned}
& p=\dot{\phi}-\dot{\psi} \sin \theta \\
& q=\dot{\theta} \cos \phi+\dot{\psi} \cos \theta \sin \phi \quad\} \\
& r=-\dot{\theta} \sin \phi+\dot{\psi} \cos \theta \cos \phi
\end{aligned}
$$

For small quantities of the first order, equation 1 becomes as:

$$
p=\dot{\phi}, \quad q=\dot{\theta}, \quad r=\dot{\psi}
$$

The state equation of sideslip angle and velocity in roll, pitch and yaw angle are in [1] as:

$$
\left.\begin{array}{l}
\dot{\beta}=Y_{v} \beta-r+g \cos \gamma_{o} / U_{o}+Y_{\delta_{R}^{\prime}} \delta_{R} \\
\dot{P}=L_{\beta^{\prime}} \beta+L_{p^{\prime}} p+L_{r^{\prime}} \cdot r+L_{\delta_{A}^{\prime}} \delta_{A}+L_{\delta_{R}^{\prime}} \delta_{R} \quad \\
\dot{r}=N_{\beta^{\prime}} \beta+N_{p} p+N_{r^{\prime}} r+N_{\delta_{A}^{\prime}} \delta_{A}+N_{\delta_{R}^{\prime}} \delta_{R} \\
\dot{\phi}=p+\tan \gamma_{o} r
\end{array}\right\}
$$


The system in matrix form is

$$
\dot{X}_{1}=A_{1} X_{1}+B_{1} u_{1}
$$

Where; the state and input vectors are defined as:

$$
X_{1}=\left[\begin{array}{llll}
\beta & p & r & \phi
\end{array}\right], \quad u_{1}=\left[\begin{array}{ll}
\delta_{A} & \delta_{R}
\end{array}\right]
$$

$A_{1}$ is the state dynamic matrix, and $B_{1}$ is the input vector of model-1

\subsection{Model-2: Effect Of The Dutch Roll Damper}

The yaw damper adds two differential equations to the classical system as:

$$
\left.\begin{array}{l}
\dot{\delta}_{R}=-\frac{1}{\tau_{R}} \delta_{R}+\frac{k_{R}}{\tau_{R}} e_{w o}+\frac{k_{R}}{\tau_{R}} r_{c} \\
e_{w o}=-\frac{1}{\tau_{w o}} e_{w o}+S_{y r g} \dot{r}
\end{array}\right\}
$$

Substitute by $\dot{r}$ from Eqn.3, the washout circuit output becomes:

$$
\dot{e_{w o}}=-\frac{1}{\tau_{w o}} e_{w o}+S_{y r g}\left(N_{\beta^{\prime}} \beta+N_{p^{\prime}} p+N_{r^{\prime}} \cdot r+N_{\delta_{A}^{\prime}} \delta_{A}+N_{\delta_{R}^{\prime}} \delta_{R}\right)
$$

Where;

$$
N_{\beta^{\prime}}, N_{p^{\prime}}, N_{r^{\prime}}, N_{\delta_{A}^{\prime}}, N_{\delta_{R}^{\prime}}, \ldots \ldots . . \text { are the system parameters }
$$

The final dutch- roll damper equations have represented as:

$$
\dot{X}_{2}=A_{2} X_{2}+B_{2} u_{2}
$$

Where; the state vector and control vector become:

$$
\begin{aligned}
& X_{2}=\left[\begin{array}{llllll}
\beta & p & r & \phi & \delta_{R} & e_{w o}
\end{array}\right]^{\prime} \\
& u_{2}=\left[\begin{array}{ll}
\delta_{A} & r_{c}
\end{array}\right]
\end{aligned}
$$

Where; $A_{2}$ is the state dynamic matrix, and $B_{2}$ is the input vector of model-2

\section{EFFICIENT FUZZY LOGIC CONTROL}

Fuzzy logic has an advantage over other control methods because it does not sensitive to plant parameter variations. The fuzzy logic control approach consists of 
three stages, namely fuzzification, fuzzy control rules engine, and defuzzification. To design the fuzzy logic to the lateral beam guidance system, the input signals are the sideslip angle deviation at sampling time and its change. In addition, the output signal has the control signal to the autopilot. Fig.2 shows the Fuzzy logic control scheme. While the fuzzy membership function signal has described in Fig. 3, and fuzzy control rules have illustrated in table.1. Fig.4 shows the complete system consists of fuzzy logic and aircraft model

\subsection{How the Fuzzy Work}

Many steps for fuzzy logic control work are as the following:

1) Define the control objectives and criteria: What do I have to do to control the system?

2) Determine the input and output relationships, and choose a minimum number of variables for input to the FLC engine (typically error and rate-of-change-of-error).

3) Using the rule-based structure of FLC, break the control problem down into a series of IF $X$ AND $Y$ THEN $Z$ rules that define the desired system output response for given system input conditions

4) Create FLC membership functions that define the meaning (values) of Input/Output terms used in the rules.

5) Create the necessary pre- and post-processing FLC routines if implementing in $\mathrm{S} / \mathrm{W}$, otherwise program the rules into the $\mathrm{FL} \mathrm{H} / \mathrm{W}$ engine.

6 ) Test the system, evaluate the results, tune the rules and membership functions, and retest until satisfactory results have obtained.

\subsection{Fuzzy Membership Function And Rules}

Membership function shapes of error and derivative error and the gains have chosen to be identical with triangular function for fuzzy logic control as shown in Fig. 3 and the range of scale from -1 to 1 , Also the number of rules is 7 . However, this horizontal axis range has taken different values because of optimizing controller. The membership function sets of FLC have shown in Fig.3.

Table 1. Fuzzy logic control rules. $\Delta \beta$

\begin{tabular}{|l|l|l|l|l|l|l|l|}
\hline \multirow{2}{*}{$\Delta \beta$} & \multicolumn{7}{|c|}{$d \Delta \beta$} \\
\cline { 2 - 8 } & LN & MN & SN & Z & SP & MP & LP \\
\hline LN & LP & LP & LP & MP & MP & SP & Z \\
\hline MN & LP & MP & MP & MP & SP & Z & SN \\
\hline SN & LP & MP & SP & SP & Z & SN & MN \\
\hline Z & MP & MP & SP & Z & SN & MN & MN \\
\hline SP & MP & SP & Z & SN & SN & MN & LN \\
\hline MP & SP & Z & SN & MN & MN & MN & LN \\
\hline LP & Z & SN & MN & MN & LN & LN & LN \\
\hline
\end{tabular}

Where;

LN: large negative membership function; MN: medium negative; SN: small negative; Z: zero; SP: small positive; MP: medium positive; LP: large positive. 


\section{OPTIMAL LQR CONTROL DESIGN}

The object of the optimal control design is determining the optimal control law $u(t, x)$ which can transfer system from its initial state to the final state such that given quadratic performance index is minimized.

$$
[K, S, E]=\operatorname{lq}(A, B, Q, R, N)
$$

Where: $Q$ is positive semi definite matrix and $R$ is real symmetrical matrix. The problem is to find the vector feedback $K$ of control law, by choosing matrix $Q$ and $R$ to minimize the quadratic performance index $\mathrm{J}$ is described by :

$$
J=\int_{0}^{\infty}\left(\Delta x^{t} Q \Delta x+\Delta u^{t} R^{-1} \Delta u\right) d t
$$

The optimal control law is written as

$$
\begin{aligned}
& \Delta \mathrm{u}(\mathrm{t})=\mathrm{K} \Delta \mathrm{x}(\mathrm{t}) \\
& K=-R^{-1} B^{t} P
\end{aligned}
$$

The matrix $P$ is positive definite, symmetric solution to the matrix Riccati equation, which has written as:

$$
P A+A^{t} P+Q-P B R^{-1} B^{t} P=0
$$

\section{OPTIMAL COMPENSATOR LQG CONTROL}

We have introduced the Kalman filter, which is an optimal observer for multi-output plants in the presence of process and measurement noise, modeled as white noises. The optimal compensator Linear Quadratic Gaussian (LQG) consists of combine between optimal LQR control and Kalman filter[11]. In short, the optimal compensator LQG design process is the following:

1- Design an optimal regulator LQR for a linear plant assuming full-state feedback (i.e. assuming all the state variables are available for measurement) and a quadratic objective function.

2- Design a Kalman filter for the plant assuming a known control input, $u(t)$, a measured output, $y(t)$, and white noises, $v(t)$ and $z(t)$. The Kalman filter is designed to improve an optimal estimate of the state-vector.

3- Combine the separately designed optimal regulator LQR and Kalman filter into an optimal compensator LQG.

4- The optimal regulator feedback gain matrix, $\mathrm{K}$, and the Kalman filter gain matrix, L, are used to complete closed compensator system LQG as follows:

From Eqn.( 7) get optimal regulator gain matrix $K$. 
Calculate the Kalman filter gain as follows. Let the system as

$$
\begin{array}{lr}
x=A x+B u+G w & \{\text { State equation } \\
y=C x+D u+v & \text { \{Measurements }
\end{array}
$$

with unbiased process noise $\mathbf{w}$ and measurement noise $\mathbf{v}$ with covariance's

$$
E\left\{w w^{\prime}\right\}=Q, E\left\{v^{\prime}\right\}=R, E\left\{w^{\prime}\right\}=N,
$$

$[L, P, E]=L Q E(A, G, C, Q, R, N)$

Returns the observer gain matrix $L$ such that the stationary Kalman filter

$$
x \_e=A x \_e+B u+L\left(y-C x \_e-D u\right)
$$

Produces an optimal state estimate $\boldsymbol{x} \_\boldsymbol{e}$ of $\boldsymbol{x}$ using the sensor measurements $\boldsymbol{y}$. The resulting Kalman estimator can be formed with estimator. The noise cross-correlation $\boldsymbol{N}$ is set to zero when omitted. Also returned are the solution $\boldsymbol{P}$ of the associated Riccati equation

$$
A P+P A^{\prime}-\left(P C^{\prime}+G^{*} N\right) R\left(C P+N^{*} G^{\prime}\right)+G^{*} Q^{*} G^{\prime}=0
$$

and the estimator poles $E=E I G(A-L * C)$.

Using MATLAB function readymade command reg to construct a state-space model of the optimal compensator LQG, given a state-space model of the plant, sysp, the optimal regulator feedback gain matrix $\boldsymbol{K}$, and the Kalman filter gain matrix $\boldsymbol{L}$. This command is used as follows:

$$
\text { sys_closed }=\operatorname{reg}(\operatorname{sysp}, K, L)
$$

Where; sys_closed is the state-space model of the LQG compensator. The final, get the system overall feedback sysCL as:

$$
\text { sysCL }=\text { feedback }(\text { sysp, } \quad \text { sys_closed })
$$

Where, sysCL is the state-space of LQG plus state-space of system with open-loop

\section{DIGITAL SIMULATION RESULTS}

The system parameters data are the following:

$$
\begin{aligned}
& L_{\beta}^{\prime}=-10.4, \quad L_{p}^{\prime}=-1.43, \quad L_{r}^{\prime}=0.929, \quad N_{\beta}^{\prime}=1.44, \quad N_{p}^{\prime}=-0.026, \quad N_{r}^{\prime}=-0.215, \\
& Y_{v}=-0.3014, Y_{\delta R}^{\prime}=0.0053, \quad L_{\delta A}^{\prime}=2.74, \quad L_{\delta R}^{\prime}=0.7, \quad N_{\delta A}^{\prime}=0.42, \quad N_{\delta R}^{\prime}=-0.67, \\
& S_{y r g}=1, \quad k_{R}=1, \quad \tau_{R}=0.1, \quad k_{A}=1, \quad \tau_{A}=0.1, \quad \tau_{w o}=1, \quad k_{c}=3.5, \quad \tau_{c}=10, \gamma_{o}=0 \\
& U_{o}=70, \quad g=9.8
\end{aligned}
$$




\subsection{Model-1:}

Substitute by this data in Eqn. 3 and matrix form in Eqn.4, the result state space of model-1 as follows:

$$
A_{1}=\left[\begin{array}{cccc}
-.3014 & 0 & -1 & 0.14 \\
-10.4 & -1.43 & 0.929 & 0 \\
1.44 & -0.026 & -0.215 & 0 \\
0 & 1 & 0 & 0
\end{array}\right], \quad B_{1}=\left[\begin{array}{cc}
0 & 0.0053 \\
2.74 & 0.7 \\
0.42 & -0.67 \\
0 & 0
\end{array}\right]
$$

Substitute by the above values in Eqn. 7, results the optimal control gain $\mathrm{K}_{1}$ and $\mathrm{S}$ are:

$$
\begin{gathered}
K_{1}=\left[\begin{array}{cccc}
-3.5647 & 7.5586 & 2.7661 & 7.6393 \\
-0.2561 & 2.3655 & -7.2921 & 2.6181
\end{array}\right], \\
S=\left[\begin{array}{cccc}
0.5585 & -0.0240 & -0.0130 & 0.0153 \\
-0.0240 & 0.0569 & -0.0113 & 0.0584 \\
-0.0130 & -0.0113 & 0.2057 & -0.0170 \\
0.0153 & 0.0584 & -0.0170 & 1.3651
\end{array}\right]
\end{gathered}
$$

Also, from Eqn.11, get of the Kalman filter gain matrix as

$$
L=\left[\begin{array}{cc}
0.4708 & -0.9313 \\
-0.9313 & 3.2436 \\
-0.0338 & 0.1577 \\
1.0905 & 0.0995
\end{array}\right], P=\left[\begin{array}{ccccc}
0.4708 & -0.9313 & -0.0338 & 1.0905 \\
-0.9313 & 3.2436 & 0.1577 & 0.0995 \\
-0.0338 & 0.1577 & 2.0197 & 8.1233 \\
1.0905 & 0.0995 & 8.1233 & 70.0289
\end{array}\right]
$$

Applied optimal LQR control signal, optimal compensator LQG control and fuzzy logic control signal to system described by Eqn.15, and using initial sideslip angle state equal to $0.05 \mathrm{pu}$., the results are depicted in Figs.(5-9).

Fig. 5 shows the sideslip angle response due to 0.05 pu disturbance with and without controller. Fig. 6 depicts the role angle responses due to 0.05 pu disturbance with and without controller. Also, Fig.7 displays the angular velocity in yaw direction response due to $0.05 \mathrm{pu}$ disturbance with and without controller. Fig. 8 shows the angular velocity in roll direction responses due to $0.05 \mathrm{pu}$ disturbance with and without controller. Fig.9.displays the sideslip angle response due to $0.05 \mathrm{pu}$ disturbance with LQR, LQG and fuzzy controller

\subsection{Model-2: (Effect Of Dutch Roll)}

Referred to Eqn. 5 and complete system in matrix form of Eqn.6, the result of $A_{2}, B_{2}$ are given as 


$$
A_{2}=\left[\begin{array}{cccccc}
-0.301 & 0 & -1 & 0.14 & 0.005 & 0 \\
-10.4 & -14.3 & 0.929 & 0 & 0.7 & 0 \\
1.44 & -0.026 & -0.215 & 0 & -0.67 & 0 \\
0 & 1 & 0 & 0 & 0 & 0 \\
0 & 0 & 0 & 0 & -10 & 10 \\
1.44 & -0.026 & -0.215 & 0 & -0.67 & -1
\end{array}\right], \quad B_{2}=\left[\begin{array}{cc}
0 & 0 \\
2.74 & 0 \\
0.42 & 0 \\
0 & 0 \\
0 & 10 \\
0.42 & 0
\end{array}\right]
$$

Substitute by the $A_{2}, B_{2}$ values in Eqn. 7 and choice matrix $Q$, the result of optimal control vector gain $\mathrm{K}_{2}$ as:

$$
K_{2}=\left[\begin{array}{cccccc}
-1.1533 & 0.2182 & 0.8205 & 0.2058 & -0.0280 & -0.0560 \\
0.3228 & -0.0077 & -0.8053 & 0.0252 & 0.0877 & 0.1880
\end{array}\right]
$$

Also, from Eqn.11, get of the Kalman filter gain matrix and matrix $P$ are:

$$
\begin{aligned}
L & =0.001^{*}\left[\begin{array}{rrr}
0.0272 & -0.1058 \\
-0.1058 & 0.6731 \\
0.0096 & -0.0816 \\
0.0915 & -0.0049 \\
0.0143 & -0.0957 \\
0.0159 & -0.0965
\end{array}\right], \\
P & =\left[\begin{array}{cccccc}
0.0003 & -0.0011 & 0.0001 & 0.0009 & 0.0001 & 0.0002 \\
-0.0011 & 0.0068 & -0.0008 & -0.0000 & -0.0010 & -0.0010 \\
0.0001 & -0.0008 & 0.0007 & 0.0031 & 0.0001 & 0.0001 \\
0.0009 & -0.0000 & 0.0031 & 0.0320 & -0.0002 & -0.0002 \\
0.0001 & -0.0010 & 0.0001 & -0.0002 & 0.0002 & 0.0002 \\
0.0002 & -0.0010 & 0.0001 & -0.0002 & 0.0002 & 0.0002
\end{array}\right]
\end{aligned}
$$

Figure 10 shows the angular velocity in roll direction response due to $0.05 \mathrm{pu}$ disturbance with and without dutch roll effects without any signal controls. Also, sideslip angle response due to 0.05 in pu disturbance with and without dutch roll effect without any signal controls (comparison of model-1 and model-2 without control) is shown in Fig.11.

Applied optimal LQR control signal, robust LQG control and fuzzy logic control signal to system described in Eqn.16, and using initial state disturbance equal to $0.05 \mathrm{pu}$., the results are depicted in Figs.(12-15). Fig.12 shows the sideslip angle response due to $0.05 \mathrm{pu}$ disturbance with different controller of model-2. Fig.13 depicts the role angle responses due to 0.05 pu disturbance with different controller of model-2. Also, Fig. 14 displays the angular velocity in roll direction responses due to $0.05 \mathrm{pu}$ disturbance with different controller of model-2. Moreover, Fig. 15 shows the angular velocity in yaw direction response due to 0.05 pu disturbance with different 
controller of model-2. Table. 2 is described the eignvalues calculation of two models with and without controllers

Table 2. Eignvalues analysis of two models with and without controllers.

\begin{tabular}{|c|c|c|c|c|}
\hline Model Type & $\begin{array}{l}\text { Without } \\
\text { controller }\end{array}$ & $\begin{array}{l}\text { Optimal } \\
\text { controller }\end{array}$ & Kalman Filter & $\begin{array}{l}\text { LQG+ Plant } \\
\text { +Feedback } \\
\text { Control }\end{array}$ \\
\hline Model-1 & $\begin{array}{l}-1.8410 \\
-0.0362+1.4387 i \\
-0.0362-1.4387 i \\
-0.0330\end{array}$ & $\begin{array}{l}-1.8479 \\
-0.0962+1.4452 i \\
-0.0962-1.4452 i \\
-0.1619\end{array}$ & $\begin{array}{l}-2.2338+2.2469 \mathrm{i} \\
-2.2338-2.2469 \mathrm{i} \\
-1.1708 \\
-0.0224\end{array}$ & $\begin{array}{l}-22.9493 \\
-5.6074 \\
-2.2338+2.2469 \mathrm{i} \\
-2.2338-2.2469 \mathrm{i} \\
-1.1708 \\
-0.9534 \\
-0.8489 \\
-0.0224\end{array}$ \\
\hline Model-2 & $\begin{array}{l}-9.1775 \\
-0.1426+1.2945 i \\
-0.1426-1.2945 i \\
-1.7284+0.1354 i \\
-1.7284-0.1354 i \\
-0.0269\end{array}$ & $\begin{array}{l}-9.7233 \\
-0.4557+1.3965 i \\
-0.4557-1.3965 i \\
-0.5395 \\
-1.5210 \\
-2.0476\end{array}$ & $\begin{array}{l}-9.1775 \\
-1.7284+0.1354 i \\
-1.7284-0.1354 i \\
-0.1430+1.2945 i \\
-0.1430-1.2945 i \\
-0.0269\end{array}$ & $\begin{array}{l}-9.1775 \\
-9.7233 \\
-0.1432+1.2946 i \\
-0.1432-1.2946 i \\
-0.4557+1.3965 i \\
-0.4557-1.3965 i \\
-0.0296 \\
-0.5395 \\
-2.0476 \\
-1.7284+0.1354 i \\
-1.7284-0.1354 i \\
-1.5210\end{array}$ \\
\hline
\end{tabular}

\section{DISCUSSION}

Tables 3, 4 are displayed that the lateral beam model under study is stable but after long time (settling time >> $50 \mathrm{Sec}$.). Using Dutch roll on the system of model-1 to increased damping oscillation (settling time equal to $30 \mathrm{Sec}$.). But this situation is not enough for dynamic stability, with the result that the fuzzy logic controller and optimal linear quadratic Guassian compensator LQG have proposed and applied to model-1 (without Dutch roll effect) and model-2 ( with Dutch roll effects). The settling time with using proposed fuzzy logic control and Dutch roll effect decreased to $13 \mathrm{Sec}$., while, $5 \%$ disturbance as a magnitude and starting time equal to $5 \mathrm{Sec} .$, . From the all state responses, show that the proposed fuzzy logic controller and robust LQG have decreased settling time and less over/under shoot than before controllers.

\section{GENERAL CONCLUSION}

Application of fuzzy logic control to the damping oscillation of lateral beam guidance autopilot system has proposed. Aircraft lateral landing autopilot structure is evaluated firstly which includes Dutch roll damper. The Dutch roll damper is damping the system but not enough for dynamic stability range. It has found that the fuzzy controller is more robust than conventional optimal controller for increasing damping 
oscillations. The fuzzy logic controller is the best controller where it is the less settling time, small over/under shoots, distance taken to coincide on the centerline of the guidance beam and is the more robust to perturbation and variation of the aircraft stability derivatives around the nominal values of them. It can be summary the main advantages of the fuzzy controllers as:

- They do not require a detail mathematical model to formulate the algorithms of the controller.

- Because of both error and error derivatives are required to evaluate the control action, the fuzzy controller has more adaptive capability.

- By using different sets of control rules, the fuzzy controller can operate for a large of inputs.

- The fuzzy logic controllers are more robust to the parametric changes than conventional optimal controller.

Also, The robust LQG controller is the best compensator in this case.

Table 3. Settling time and over/under shoots calculation of sideslip angle response due to 0.05 pu. Disturbance of Model-1.

\begin{tabular}{|l|l|l|l|l|}
\hline & $\begin{array}{l}\text { Without } \\
\text { control } \\
\text { Model-1 }\end{array}$ & $\begin{array}{l}\text { Optimal } \\
\text { control }\end{array}$ & Fuzzy control & LQG- Control \\
\hline $\begin{array}{l}\text { Settling } \\
\text { time (Sec.) }\end{array}$ & > 50 Sec. & 42 Sec. & 30 Sec. & 30 Sec. \\
\hline $\begin{array}{l}\text { Over shoot } \\
\text { in (pu.) }\end{array}$ & 0.052 & 0.05 & 0.05 & 0.05 \\
\hline $\begin{array}{l}\text { Under } \\
\text { shoot (pu.) }\end{array}$ & -0.04 & -0.035 & -0.03 & 0.0 \\
\hline $\begin{array}{l}\text { Disturbance } \\
\text { start time } \\
\text { (Sec.) }\end{array}$ & 5 Sec. & 5 Sec. & 5 Sec. & 5 Sec. \\
\hline
\end{tabular}

Table 4. Settling time and over/under shoots calculation of sideslip angle response due to $\mathbf{0 . 0 5}$ pu. Disturbance of Model- 2 .

\begin{tabular}{|l|l|l|l|l|}
\hline & $\begin{array}{l}\text { (model-2) } \\
\text { Without } \\
\text { control }\end{array}$ & $\begin{array}{l}\text { Optimal } \\
\text { control }\end{array}$ & Fuzzy control & LQG- Control \\
\hline $\begin{array}{l}\text { Settling } \\
\text { time (Sec.) }\end{array}$ & $27 \mathrm{Sec}$. & $17 \mathrm{Sec}$. & $13 \mathrm{Sec}$. & 10 Sec. \\
\hline $\begin{array}{l}\text { Over shoot } \\
\text { in (pu.) }\end{array}$ & 0.05 & 0.05 & 0.05 & 0.045 \\
\hline $\begin{array}{l}\text { Under } \\
\text { shoot (pu.) }\end{array}$ & -0.033 & -0.03 & -0.022 & -0.02 \\
\hline
\end{tabular}




\section{REFERENCES}

[1] Mostafa Ahmed Mohamed "Studies in Indirect Self-Organizing Fuzzy Logic Control with Application to the Lateral Landing Autopilot", Master Thesis, Faculty of Engineering, Cairo University, Egypt, (1998).

[2] B. A. Wakileh and K. F. Gill, "Use of Fuzzy Logic in Robotics", Elsevier Science Publishers B. V. (North-Holland), computer in industry, Vol. No. 10, pp. 35-46, (1988)

[3] A. W. Babister "Aircraft Dynamic Stability and Response", book, London(1980).

[4] John D. Anderson "Introduction to Flight”, book, copyright by McGraw-Hill(1978).

[5] E. L. Houghton and N. B. Carruthers "Aerodynamics for Engineering Students", book, Third Edition, (1982).

[6] Ali M. Yousef. and Ayman A. Aly "Fuzzy Logic Load Frequency Controller for Single and Two-Area Power Systems with System non-Linearity", MEATIP4 , International conference of Mechanical Engineering, Assiut University, Egypt, Dec.- (2006)

[7] 3- M.K. El-Sherbiny, Ali M. Yousef, and G.El-Saady " Efficient fuzzy logic load-frequency control" Energy Conversion and Management Journal, Vol. 43, Issue No. 14, PP. 1853-1863, September (2002).

[8] Ali M. Yousef "Multi-machine power system stabilizer based on Fuzzy logic control" Journal of Engineering sciences, Faculty of Engineering, Assiut University, Vol. 32-No.2, pp. 655-664, April (2004).

[9] Ali M. Yousef and Mansour A. Mohamed "Multimachine Power System Stabilizer Based on Efficient Two-Layered Fuzzy Logic Controller" published in international conference of information technology ICIT'2004 proceeding, Istanbul, Turkey, pp. 137-140, (2004).

[10] "MATLAB Math Library User's Guide", by the Math Works. Inc., (2006).

[11] Ashish Tewari " Modern Control Design",book, copyright, 2002, John Wiley ISBN : 0471496790 


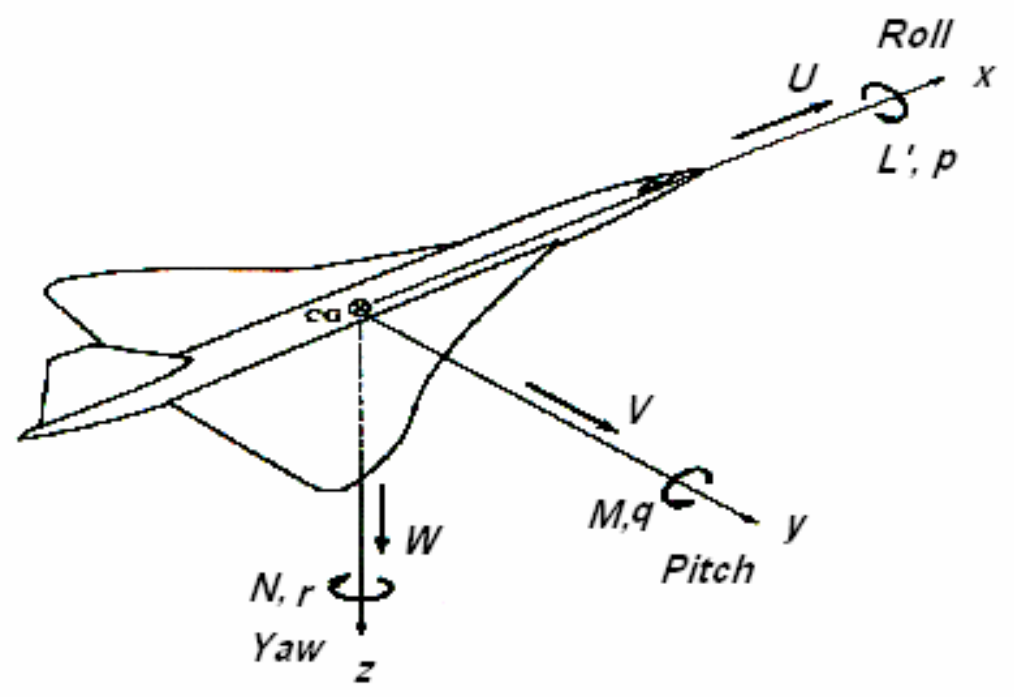

Fig. 1-a. Definition of the airplane's axes along with the translational and rotational motion along and about these axes.

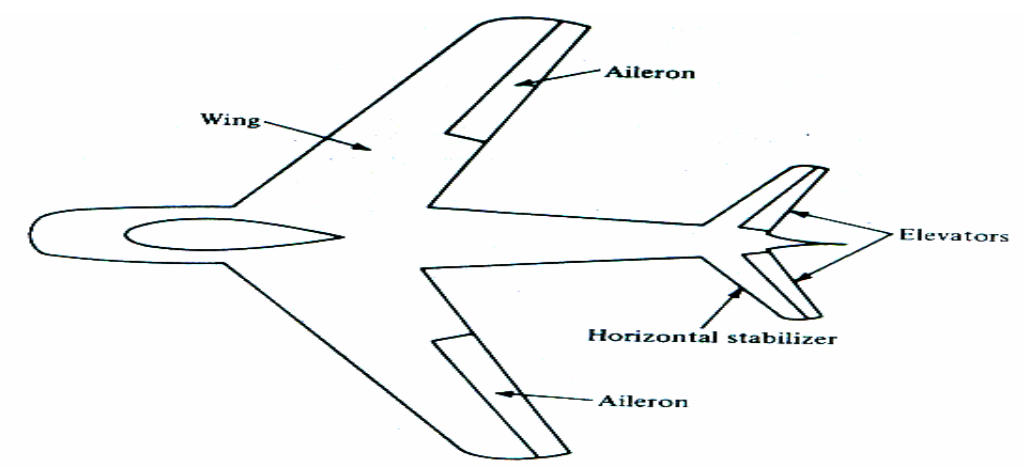

Fig. 1-b. Airplane's elevators, aileron, and horizontal stabilizer

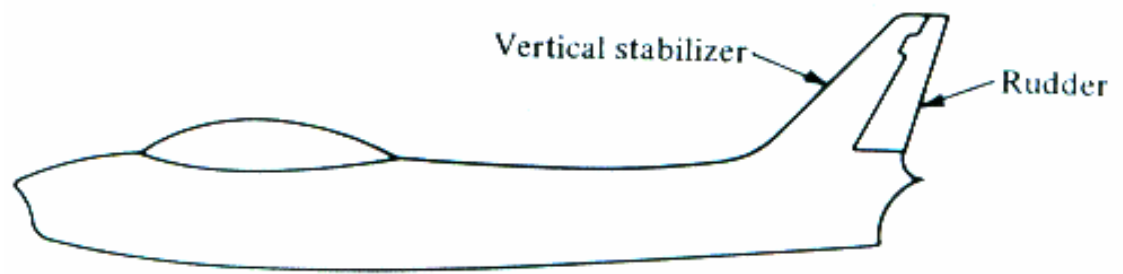

Fig. 1-c. Airplane's rudder and vertical stabilizer 


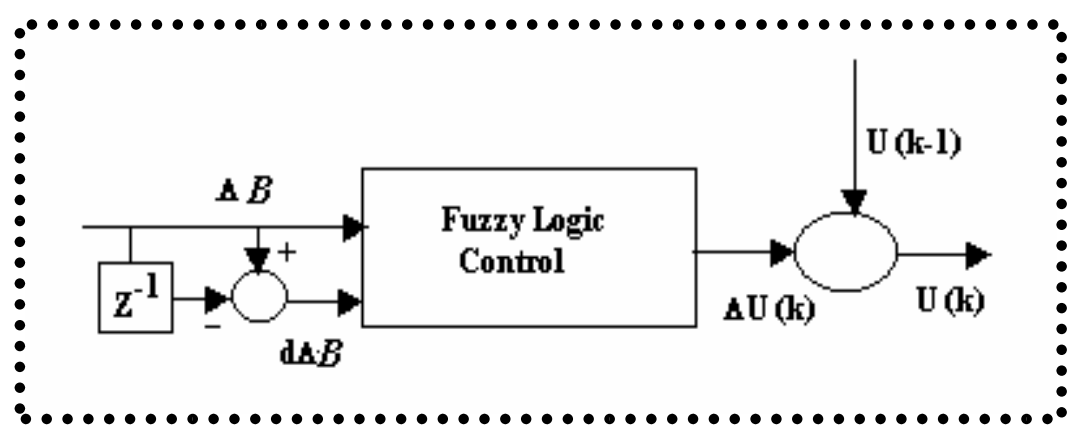

Fig. 2. Fuzzy logic control

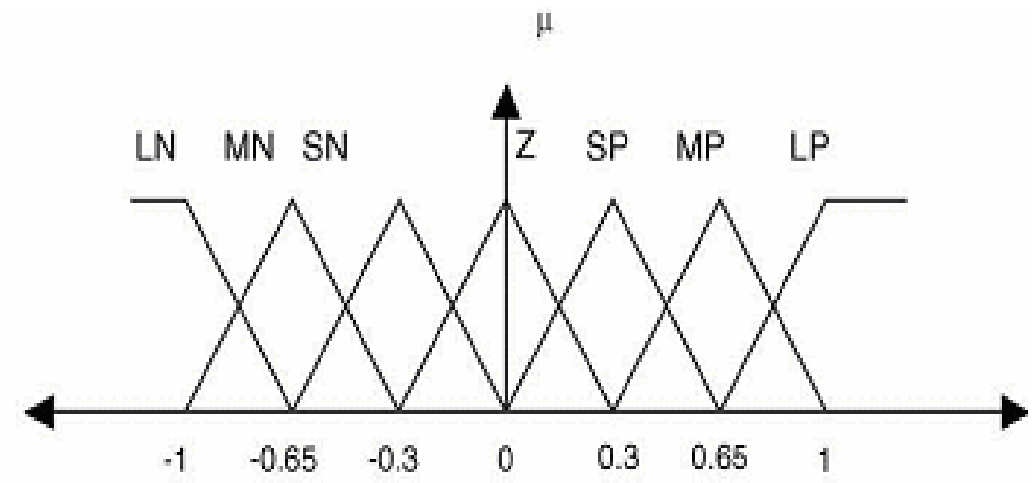

Fig. 3. The features of a triangular membership function (input and output)

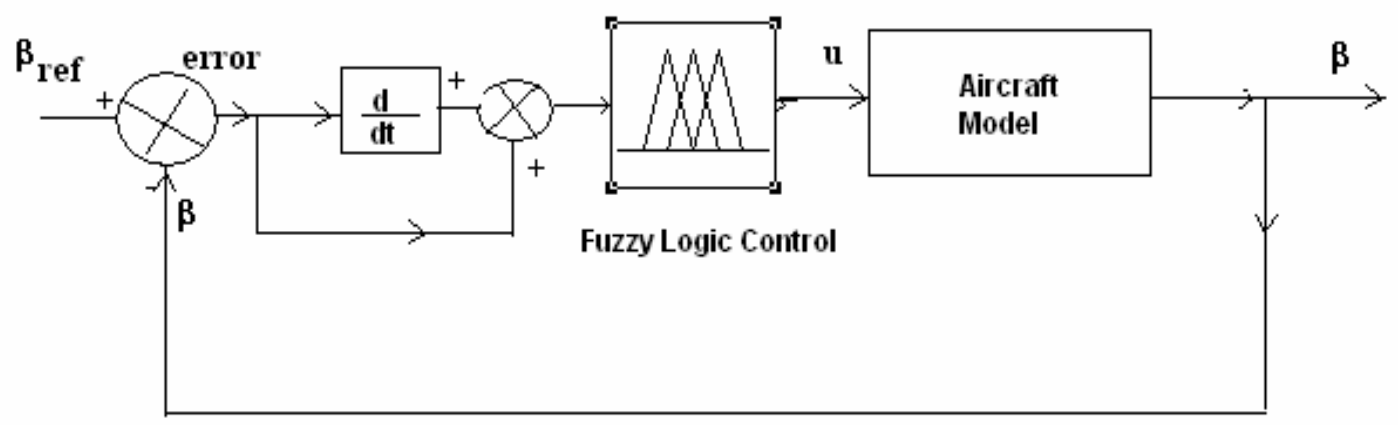

Fig.4. Fuzzy control to the aircraft model 


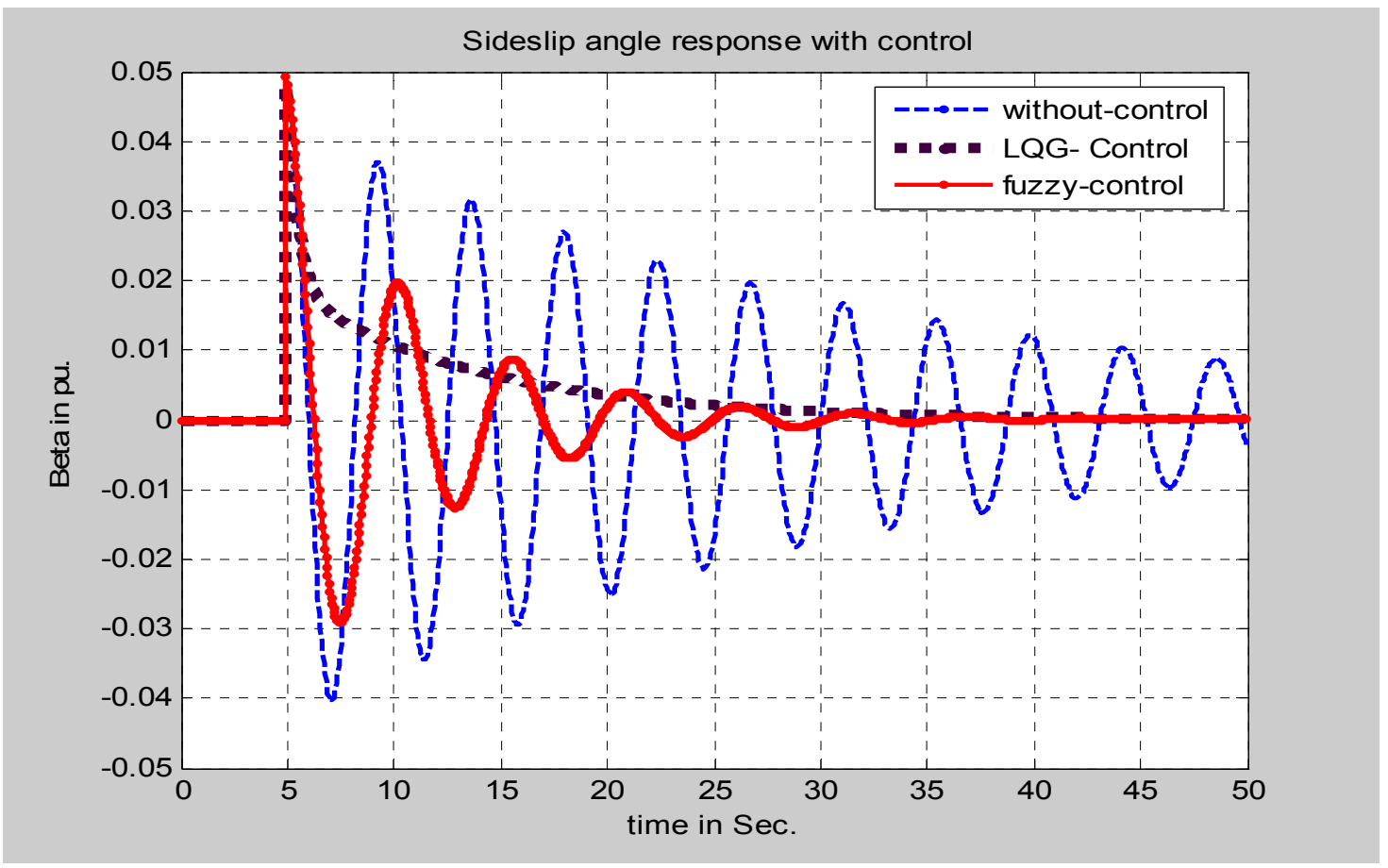

Fig.5. Side slipping angle response due to 0.05 pu disturbance with and without controller (model-1)

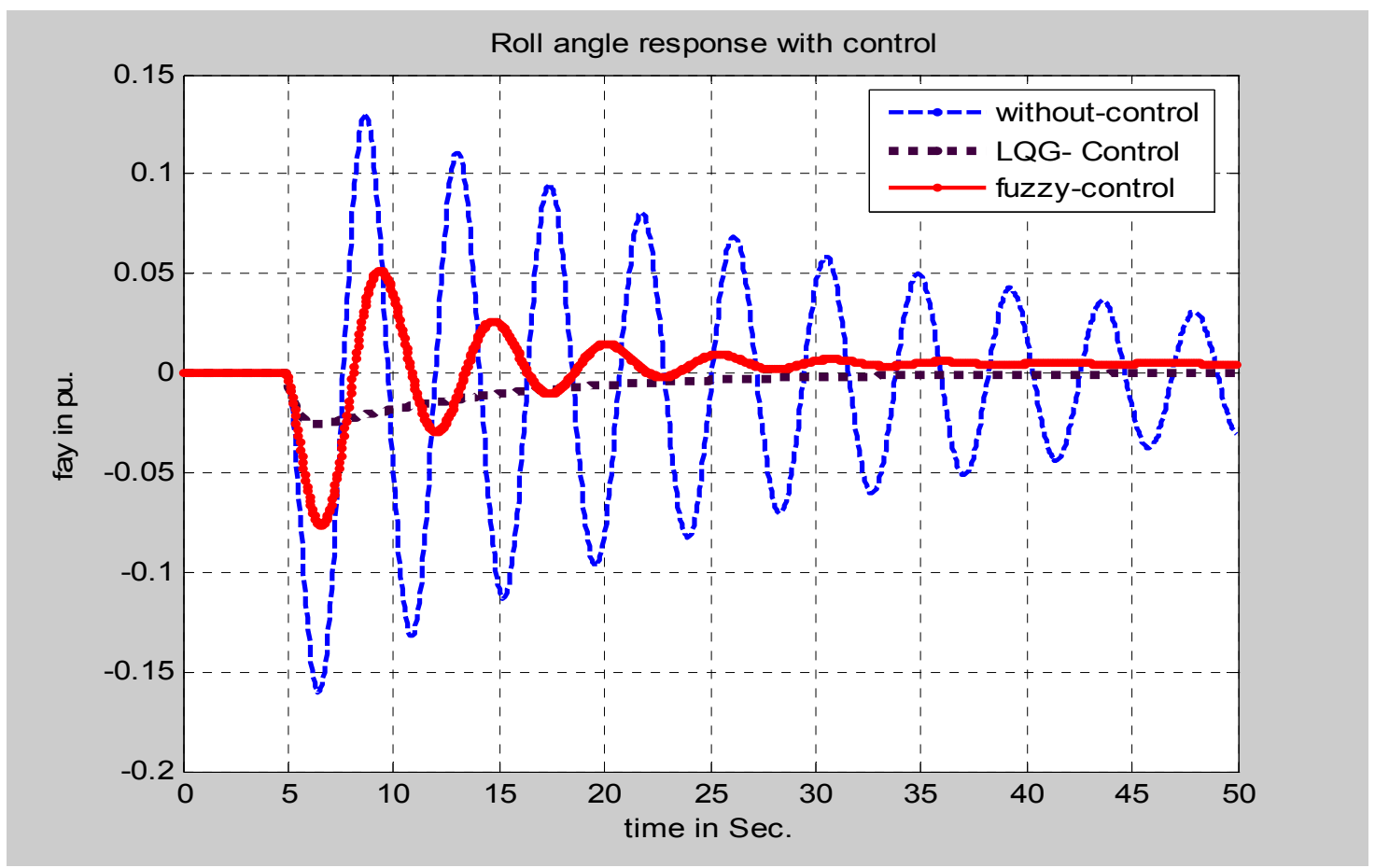

Fig.6. Role angle responses due to 0.05 pu disturbance with and without controller (model-1) 


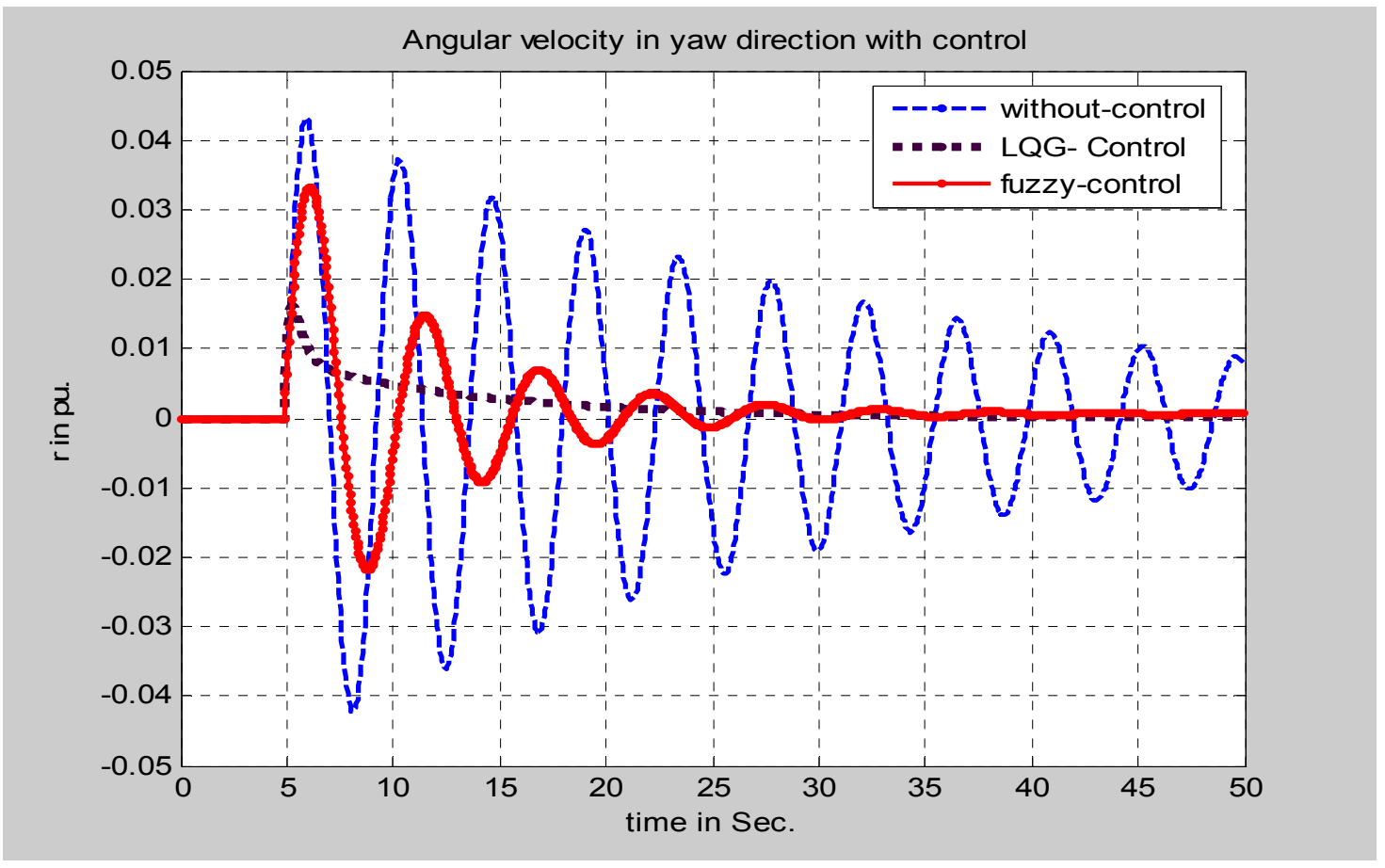

Fig.7. Angular velocity in yaw response due to $0.05 \mathrm{pu}$ disturbance with and without controller (model-1)

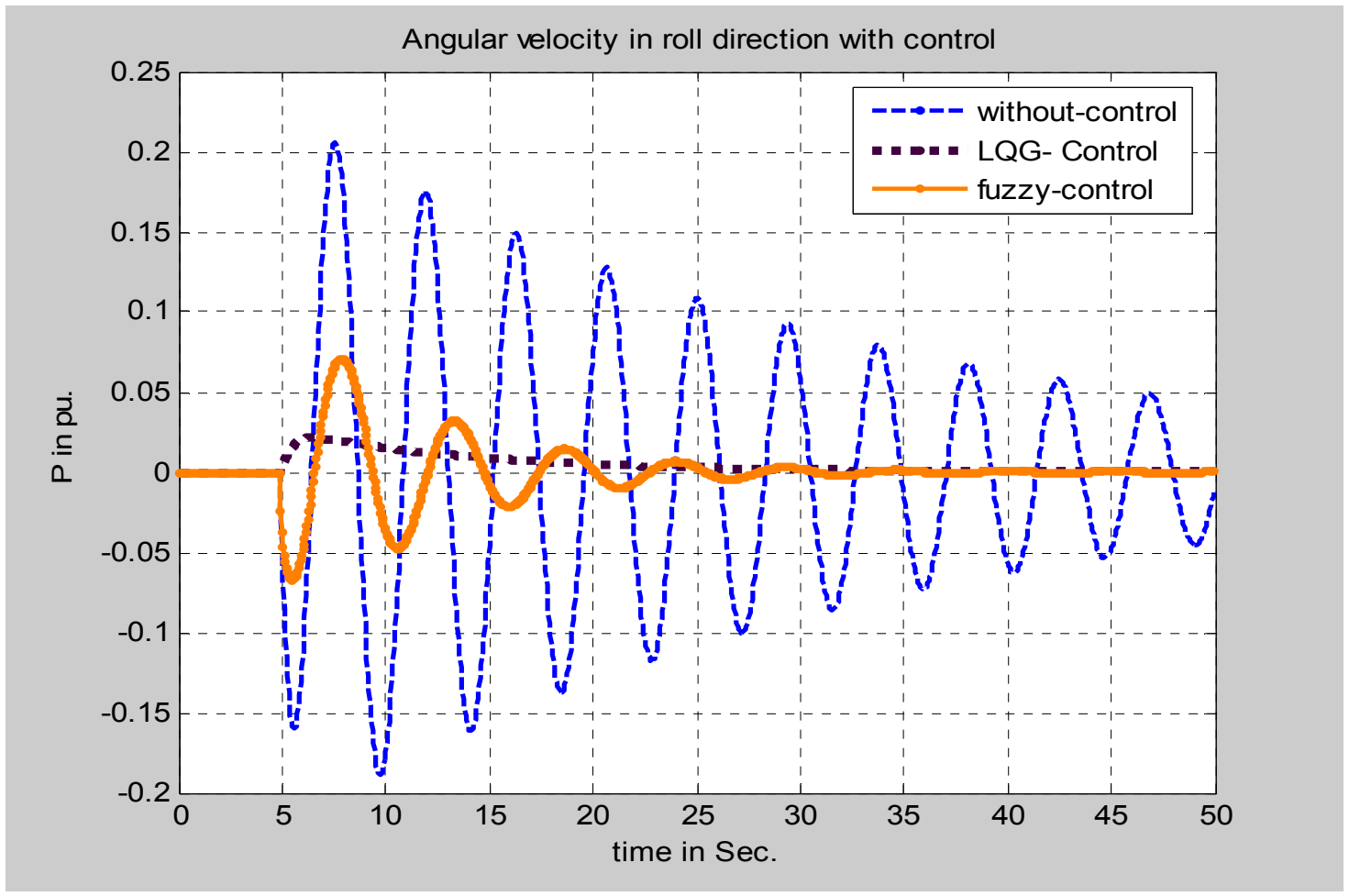

Fig.8. Angular velocity in roll responses due to $0.05 \mathrm{pu}$ disturbance with and without controller (model-1) 


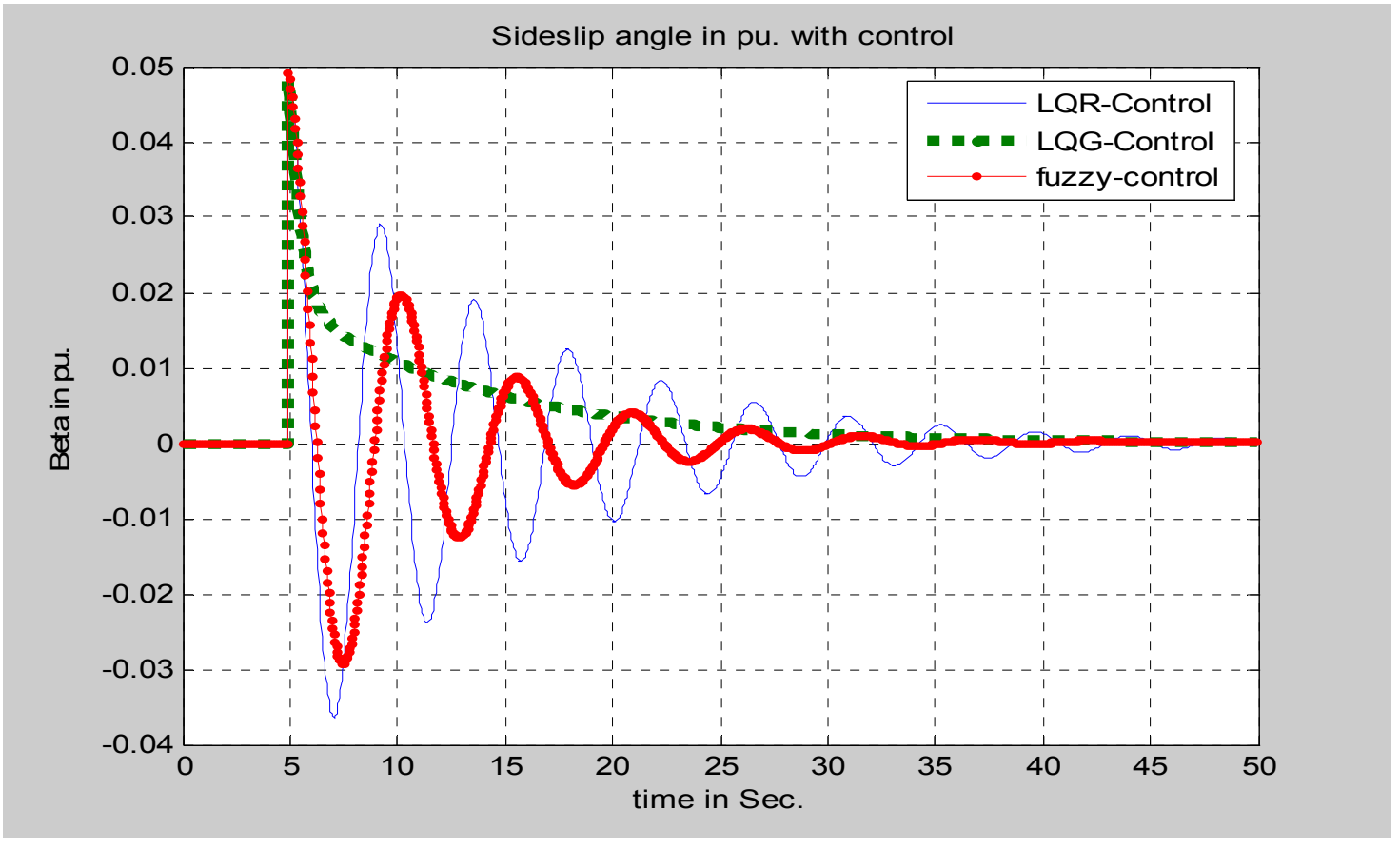

Fig.9. Sideslip angle response due to 0.05 pu disturbance with different controller (model-1)

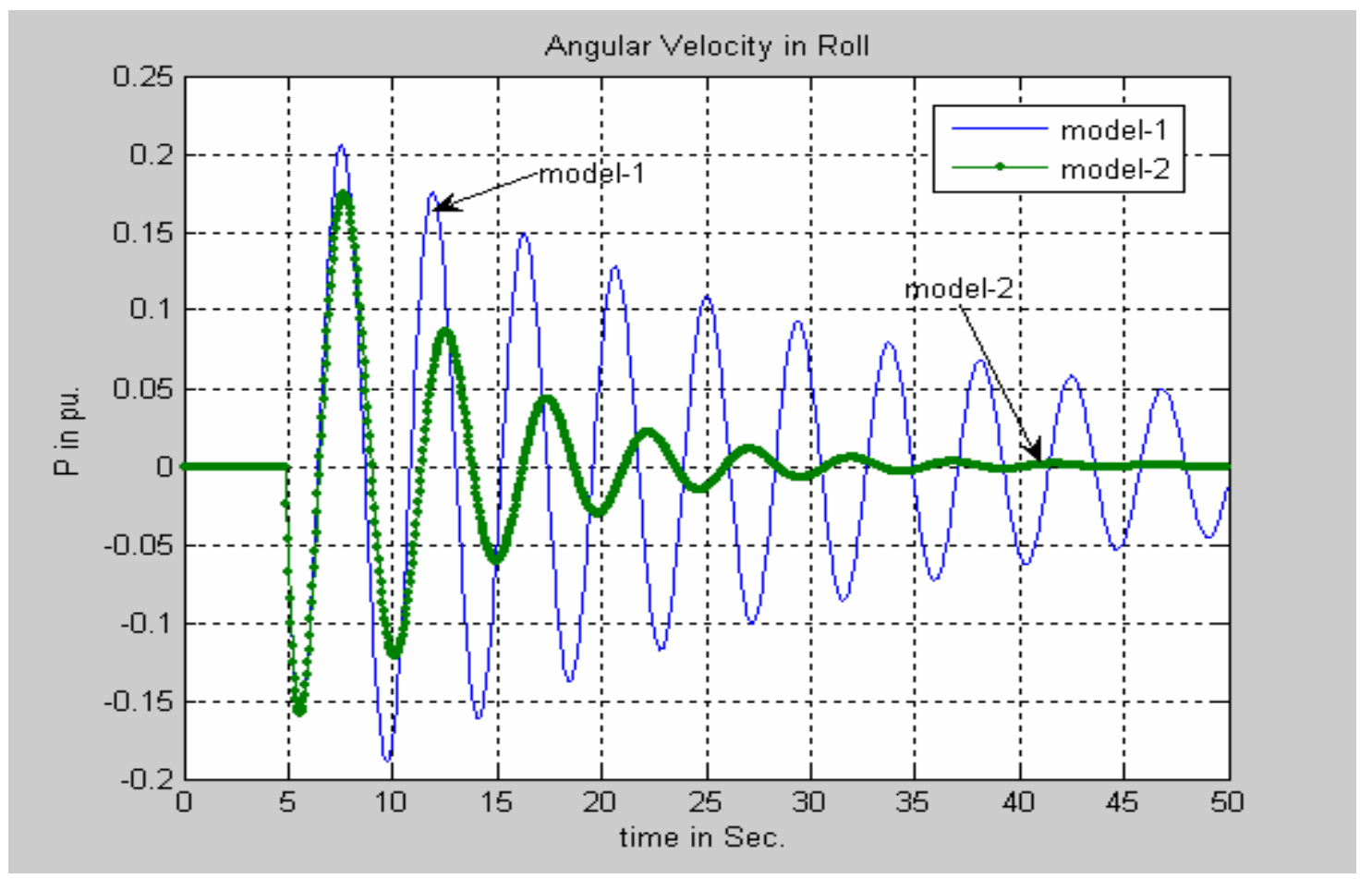

Fig. 10. Angular velocity in roll response due to 0.05 pu disturbance with and without dutch roll effect (comparison of model-1 and model-2) without control 


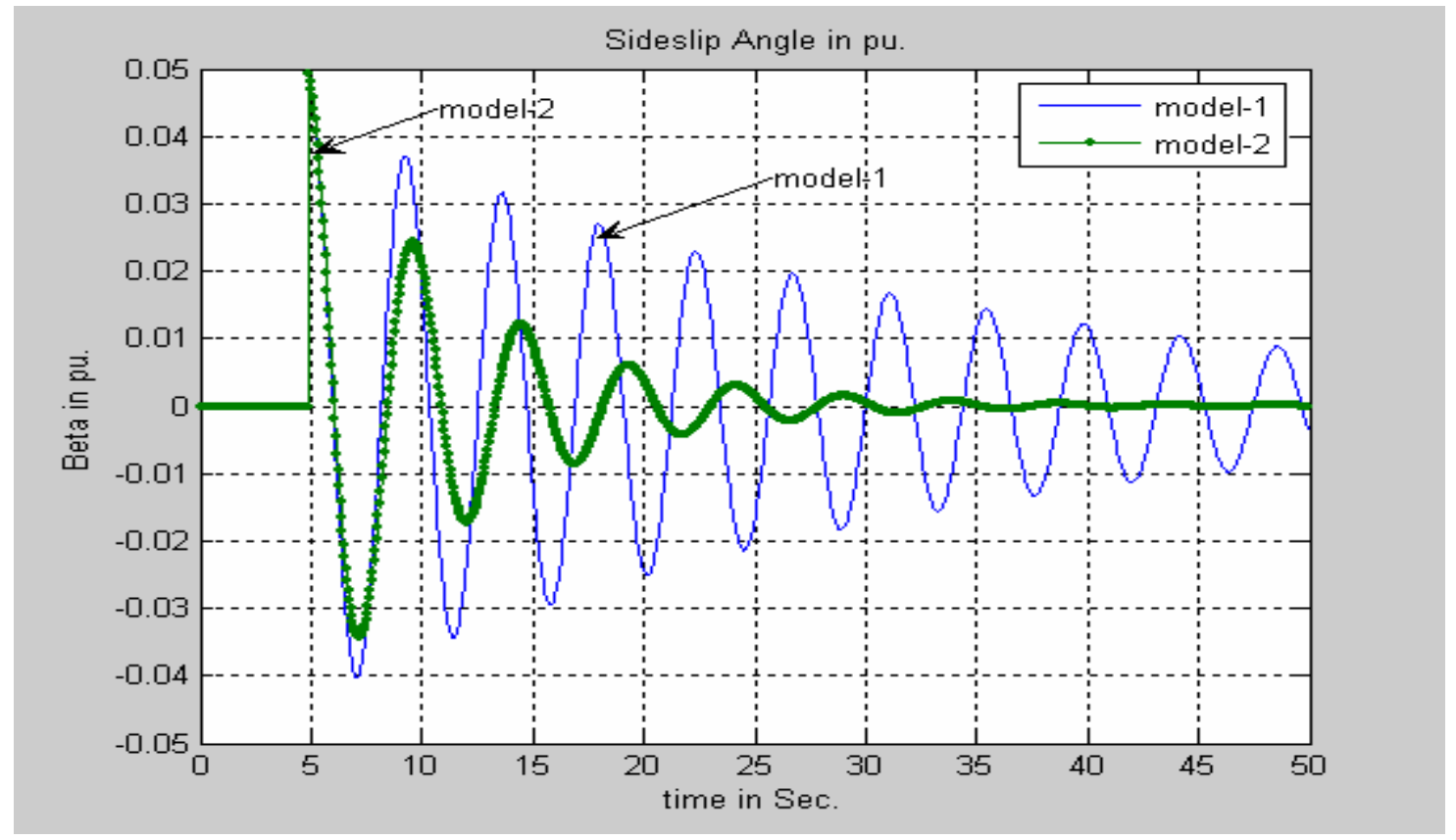

Fig.11. Sideslip angle response in pu. due to 0.05 disturbance with and without dutch roll effect (comparison of model-1 and model-2) without control

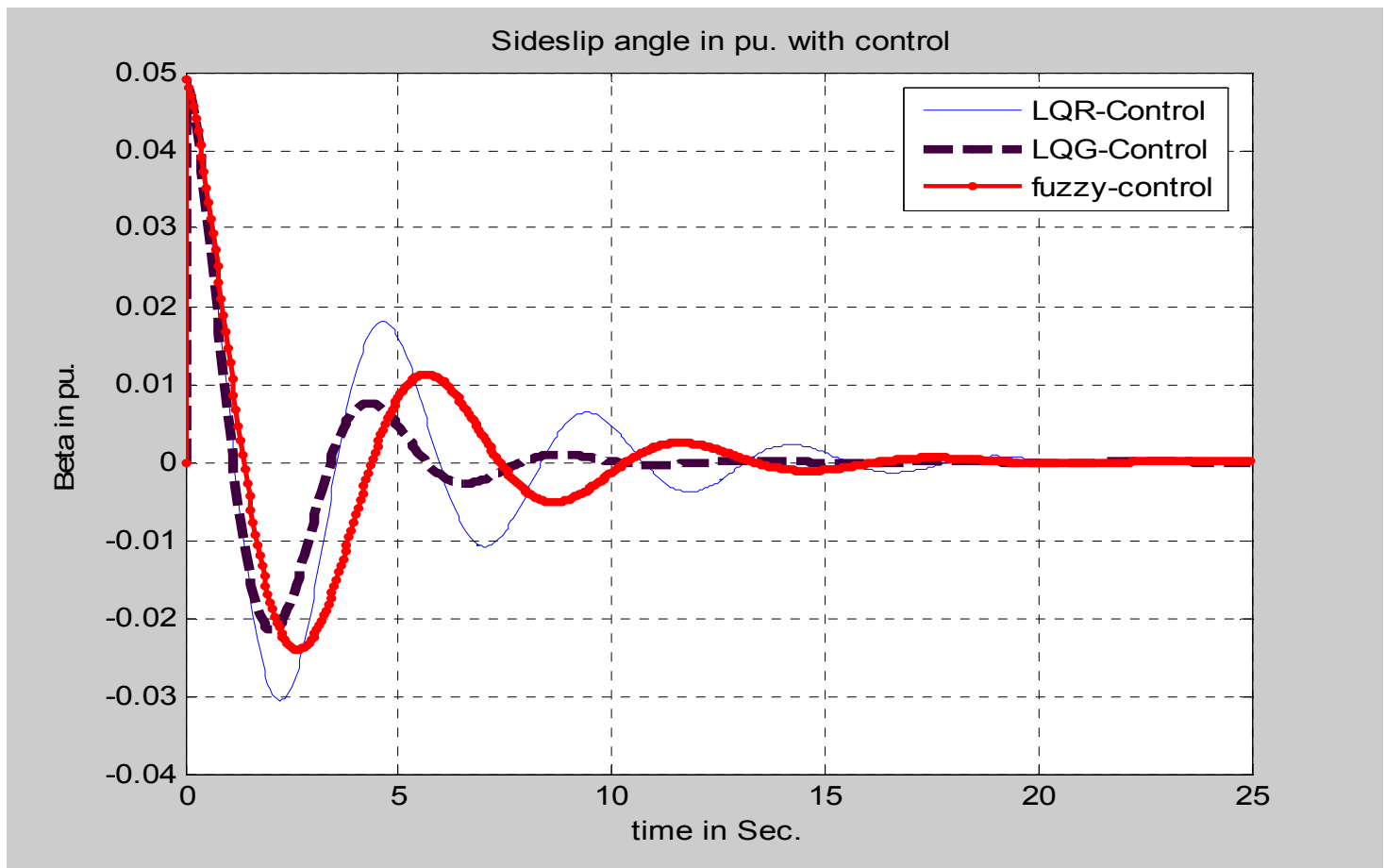

Fig.12. Sideslip angle response due to 0.05 pu disturbance with different controller (model-2) 


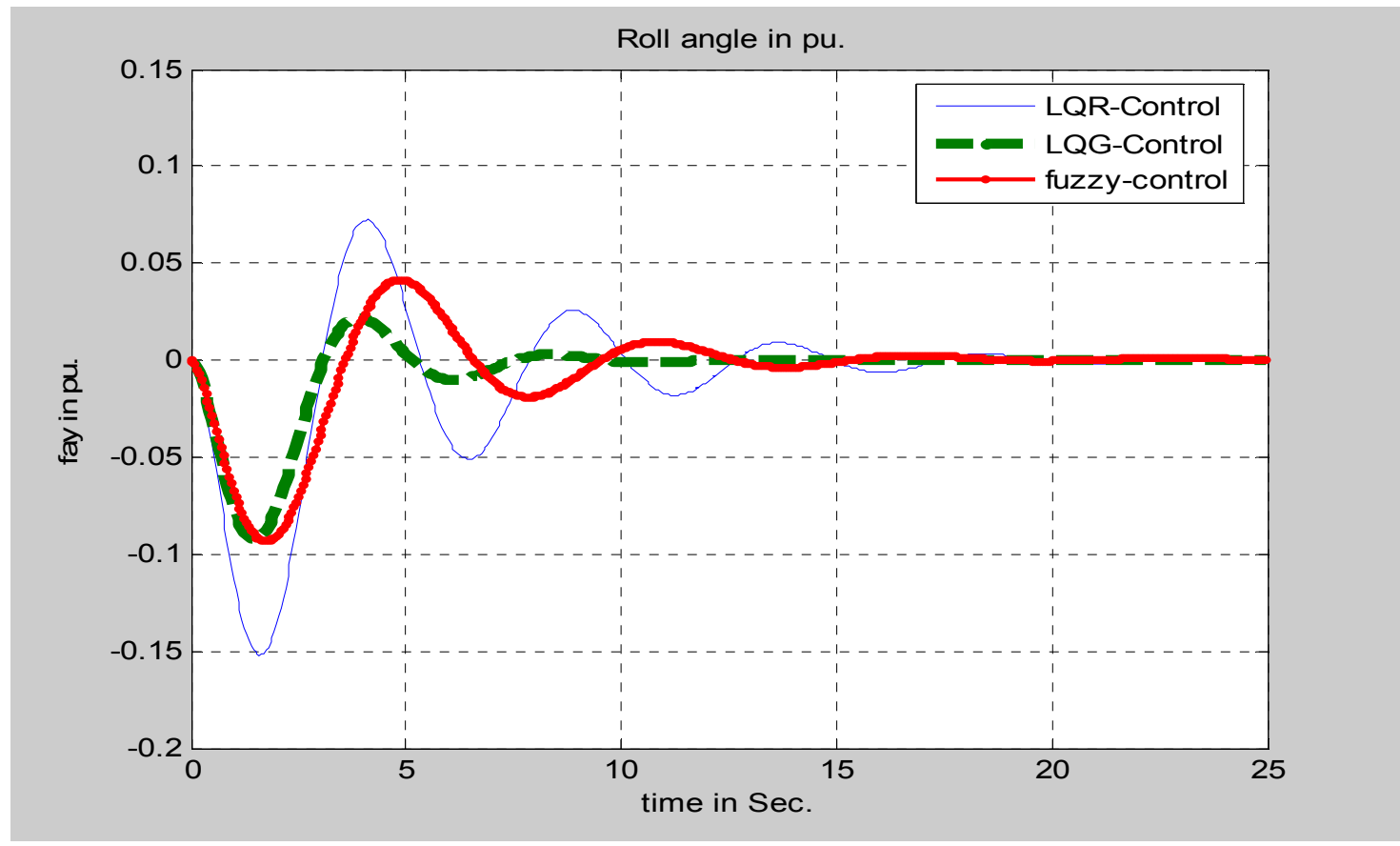

Fig.13. Role angle responses due to 0.05 pu disturbance with different controller (model-2)

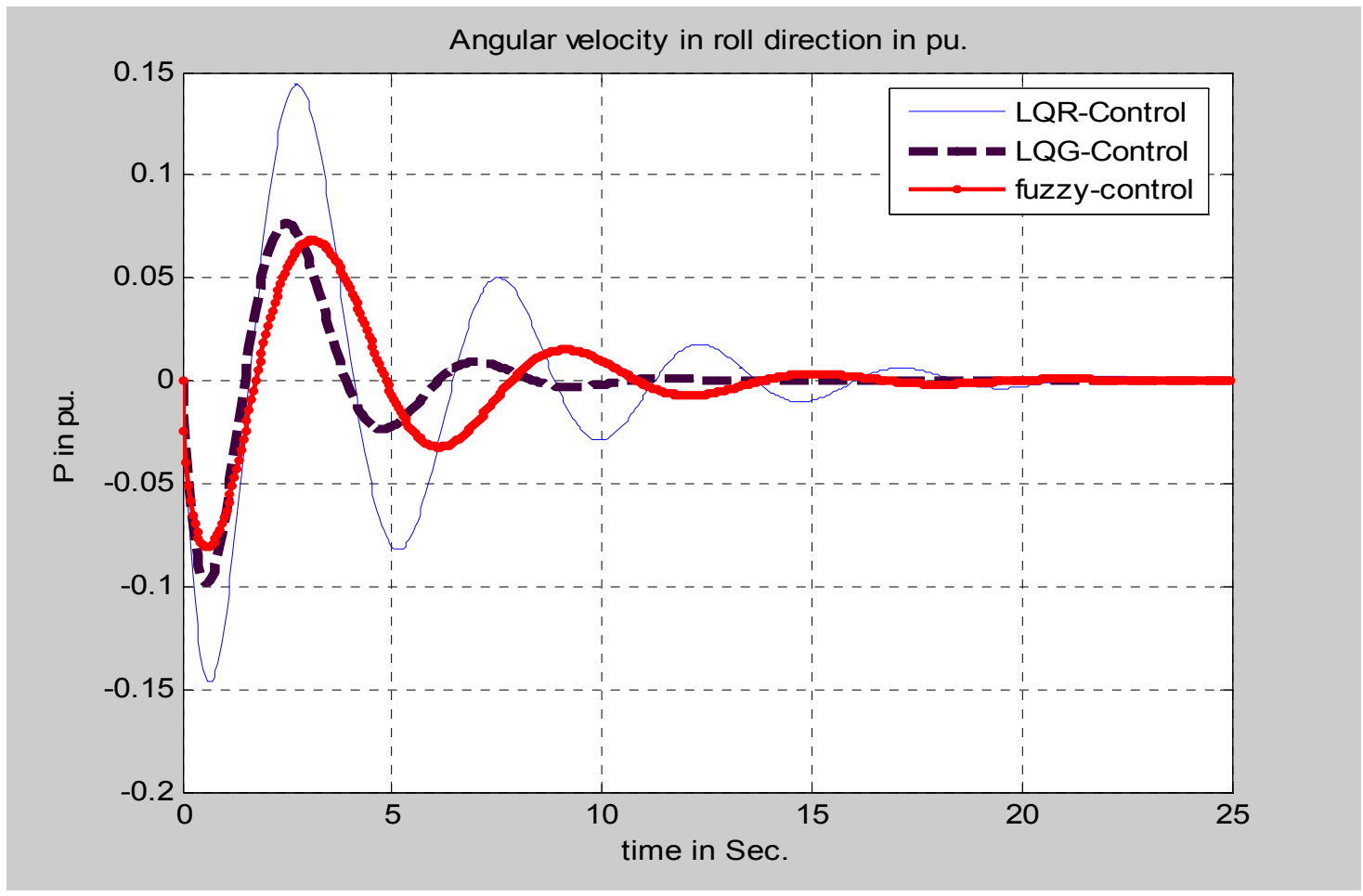

Fig. 14. Angular velocity in roll responses due to $0.05 \mathrm{pu}$ disturbance with different controller (model-2) 


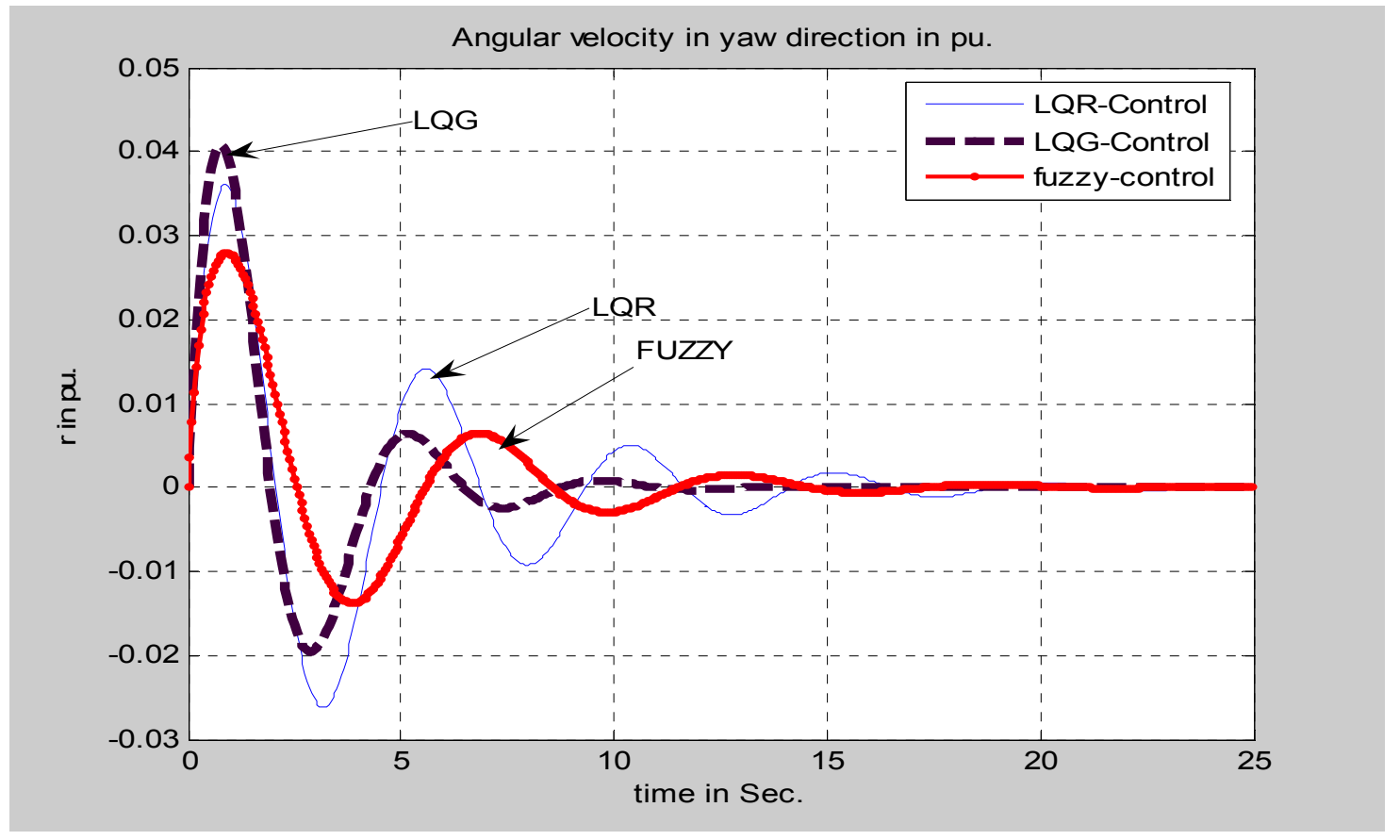

Fig. 15. Angular velocity in yaw direction response due to $0.05 \mathrm{pu}$ disturbance with different controller (model- 2) 